\section{Response from the authors}

Sir,

With reference to our recent paper [1], Vaandrager et al. report that they were unable to detect islet cell antibodies in 242 patients with proven mumps infection nor in 149 children before and after mumps vaccination. Taking our observations into consideration, this firiding is not surprising. We reported that the children investigated post mumps infection did not show positive islet cell antibody (ICA) results over the past years up to now. The seven children who developed diabetes mellitus after mumps vaccination - at least five cases with the Jeryl Lynn strain (Behring Werke AG, Marburg), four cases with proven ICA - were just seen by chance out of many thousands of children who had been vaccinated in the same period of time in different areas. Therefore, we would not expect positive findings by testing several hundred vaccinated children. As we stated in our paper, it would involve a prospective study of considerable dimensions to prove or disprove a relationship between the viral infection or vaccination and the development of diabetes mellitus.

Vaandrager et al. make some interesting suggestions in connection with their observations. We would like to comment on them as follows: We did not "postulate" that mumps vaccination may cause diabetes nor that the reported mild virus infections cause the disease. In contrast, we stated that we did not believe that the cases observed by us, as well as those described by other authors in connection with recent viral infections, were caused by such a preceding infection. It might, however, be one final insult during ongoing autoimmune processes which were induced years before - probably in utero - by contact with similar viral antigens. Thus, we hypothesized that those observations possibly point towards one of the pathogenic mechanisms rather than being pathogenic themselves.

We agree that technical differences could be the reason for the discrepancy of results between our time-limited observation on unfixed frozen sections of human pancreas and that of Ratzmann et al. [2], who used formalin fixed sections and subsequently reported a high incidence of positive ICA after mumps infection. However, the discrepancies between our study group and the groups of Vaandrager et al. and Richens et al. [3] are in our opinion more likely due to different environmental factors than to technical reasons.

One observation we made during our mumps control study could illustrate our point of view concerning the relationship between mumps infection and development of Type 1 (insulin-dependent) diabetes mellitus. Figure 1 shows the ICA in a 10 -year-old boy who developed mumps infection. He had suffered from diabetes mellitus since his second year of life. Investigations for islet cell antibodies over 15 months before mumps infection repeatedly showed borderline or negative results. After mumps infection the ICA increased very strongly up to $1: 128$ with transient complement fixation in the higher titre ranges over 7 month. After this period of time the titre decreased, complement fixation disappeared, and the borderline ICA concentration persisted again. Although this is only a single case, it could be interpreted as a further indication that certain viruses could reactivate immune reactions probably by triggering sensitized lymphocytic cell clones with specific receptor sites even in the absence of specific antigens. Since there was no indication of a polyclonal stimulation, it

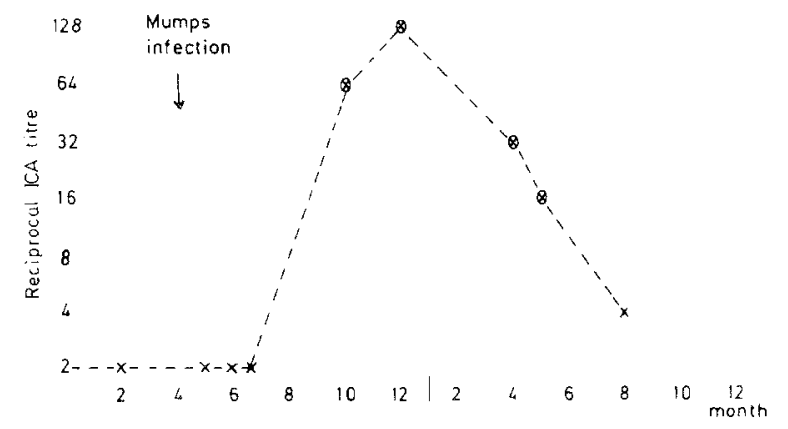

Fig. 1. $x=I C A ; \otimes=F-I C A$ could be an example of an immune reaction against endogenous agents induced by an exogenous factor.

In conclusion, we feel that the observations of Vaandrager et al. fit our concept very well. Virus infections observed shortly, i.e. a few weeks, before onset of overt diabetes mellitus seem highly unlikely to be the main cause for the onset of diabetes. Even if autoimmune reactivity against islet cells is detectable, it does not necessarily lead to islet cell destruction in diabetes mellitus. The initial insult which led to autoaggression against islets of Langerhans took place probably years before diabetes manifestation. Thus, the observed autoimmune phenomenon at the time of manifestation could just give some indication of the inducing mechanisms without necessatily being pathogenic itself.

We agree with the statement of Vaandrager et al. that, before mumps vaccination with any other strain is considered, a study for possible induction of anti-islet-cell immune reactivity would be necessary.

Yours sincerely,

K. Helmke, K. Federlin, A. Otten and W. R. Willems

\section{References}

1. Helmke K, Otten A, Willems WR, Brockhaus, Mueller-Eckhardt G, Stief T, Bertrams J, Wolf H, Federlin K (1986) Islet cell antibodies and the development of diabetes mellitus in relation to mumps infection and mumps vaccination. Diabetologia 29: 30-33

2. Ratzmann KP, Strese J, Witt S, Berling H, Keilacker H, Michaelis D (1984) Mumps infection and insulin-dependent diabetes mellitus (IDDM) Diabetes Care 7:170-173

3. Richens ER, Jones WG (1981) Islet cell antibodies and mumps. Lancet 2: 507-508 (Letter)

\section{Dr. K. Helmke}

Department of Internal Medicine

University of Giessen

6300 Giessen

FRG

\section{Obesity and Type 2 (non-insulin-dependent) diabetes}

\section{Dear Sir,}

Every medical student knows that the incidence of Type 2 (non-insulin-dependent) diabetes is related to obesity, and the study of Modan et al. [1] confirms this. However, the authors are too modest. To my knowledge, only one previous study [2] has related the incidence of diabetes to categories of relative body weight, and the results were of limited value: the population studied was confined to men aged $40-49$, there were only 44 incident cases, and they were not derived from systematic screening or case finding. Although Modan et al. [1] do not distinguish between diabetic patients diagnosed because of symptoms and those diagnosed in their systematic follow-up examination, their results imply that 10 -year incidence rates are similar (their Fig. 1) across the body mass index (BMI) distribution below a value of 31 .

A recent study of heights and weights of adults in Great Britain [3] showed that for all ages (16-64 years) $6 \%$ of men and $8 \%$ of women had a BMI exceeding 30. Assuming that the Israeli findings can be extrapolated to the British population, it would appear that the great majority of our Type 2 diabetic patients would arise from those with a BMI of less than 31 , amongst whom, continuing the extrapolation, BMI (or obesity) is not the the principal factor determining the diabetes. Perhaps, revolutionary thought, it is not a factor at all! 
Thus, the study of Modan et al [1], while confirming the consensus view that (extreme) obesity is a determinant of Type 2 diabetes, also stimulates investigators to look for the other, less obvious, factors.

Yours sincerely,

R. J. Jarrett

\section{References}

1. Modan M, Karasik A, Halkin H, Fuchs Z, Lusky A, Shitrit A, Modan B (1986) Effect of past and concurrent body mass index on prevalence of glucose intolerance and Type 2 (non-insulin-dependent) diabetes and on insulin response: the Israeli study of glucose intolerance, obesity and hypertension. Diabetologia 29: 82-89

2. Westlund K, Nicolaysen R (1972) Ten-year mortality and morbidity related to serum cholesterol. Scan J Clin Lab Invest 30 (Suppl 127): $1-24$

3. Knight I (1984) The heights and weights of adults in Great Britain. HMSO, London, monograph

Professor R. J. Jarrett

Department of Community Medicine,

United Medical and Dental Schools of

Guy's and St. Thomas's Hospitals

Guy's Campus

London Bridge

London SE1 9RT, UK

\section{Response from the authors}

Dear Sir,

Dr. Jarrett's point that a sizeable portion of patients with Type 2 (non-insulin-dependent) diabetes is not related to obesity is well taken. However, his conclusions from our data are overstated. Firstly, as reported [1], our analysis concentrated only on the 132 newly found diabetic patients detected by the oral glucose tolerance test in the course of the study. This mode was chosen for the obvious reason that weight reduction is a mainstay of treatment as well as a frequent outcome of diabetes at its more advanced stages, so that, in diabetic patients under medical follow-up, the pre-existing interrelationship with past and concurrent body mass index is altered. The 247 previously known diabetic patients in our sample were consequently excluded from the study group and their association with body mass index was not presented. Secondly, while there was a sharp increase in risk for diabetes associated with past body mass index $\geq 31$, there was a milder but continuous increase in risk throughout the body mass index range. This increase may have been less evident in Figure 1 of our report, due to the scale chosen to accomodate the total rate of glucose intolerance in the same graph. It was, however, documented and shown to be significant in Tables 3 and 4 .

Table 1 in this letter presents the rates of both newly found and previously known diabetic patients as well as of the rate of the total group with glucose intolerance (borderline + impaired + diabetes by National Diabetes Data Group Criteria [1]) in our sample, in successive 2-U intervals of past body mass index. Presentation by past body mass index was chosen here since our report indicates that this and not the concurrent body mass index determines the risk for diabetes. It should be noted that this table comprises the total sample, while in Figure 1 of the report only individuals who were not known diabetic patients and whose body mass index stayed within the same two-unit interval in both time points were included. A continuous increase throughout the body mass index range with a sharp increase when body mass index reaches values above 31 is evident in both Type 1
Table 1. Prevalence of newly found diabetes, previously known diabetes and glucose intolerance in a representative sample $(n=2387)$ of the Israeli Jewish population aged $40-70$, examined by oral glucose tolerance test (OGTT), according to past body mass index examined 10 years before the OGTT

\begin{tabular}{|c|c|c|c|c|c|c|}
\hline \multirow[t]{2}{*}{ Age } & \multirow{2}{*}{$\begin{array}{l}\text { Total } \\
\text { examined } \\
n\end{array}$} & \multicolumn{3}{|c|}{ Diabetes } & \multirow{2}{*}{$\begin{array}{l}\text { Glucose } \\
\text { intolerance } \\
\%\end{array}$} & \multirow{2}{*}{$\begin{array}{l}\text { Ratio of } \\
\text { diabetes: } \\
\text { abnorma } \\
\text { tolerance }\end{array}$} \\
\hline & & $\begin{array}{l}\text { New } \\
\%\end{array}$ & $\begin{array}{l}\text { Known } \\
\%\end{array}$ & $\begin{array}{l}\text { Total } \\
\%\end{array}$ & & \\
\hline$<21$ & 317 & 2.2 & 3.5 & 5.7 & 25.6 & $1: 3.5$ \\
\hline $21.0-22.9$ & 368 & 2.2 & 5.4 & 7.6 & 26.6 & $1: 2.5$ \\
\hline $23.0-24.9$ & 545 & 6.1 & 6.2 & 12.3 & 34.7 & $1: 1.8$ \\
\hline $25.0-26.9$ & 468 & 4.5 & 12.4 & 16.9 & 41.2 & $1: 1.4$ \\
\hline $27.0-28.9$ & 318 & 9.1 & 13.5 & 22.6 & 51.9 & $1: 1.3$ \\
\hline $29.0-30.9$ & 177 & 7.3 & 16.9 & 24.2 & 53.1 & $1: 1.2$ \\
\hline$\geq 31$ & 194 & 10.8 & 26.3 & 37.1 & 63.4 & $1: 0.7$ \\
\hline
\end{tabular}

and Type 2 diabetes. Moreover, the likelihood of developing diabetes among glucose intolerant subjects seems to increase with increasing obesity. This is indicated by the increasing ratio of diabetes to abnormal tolerance (borderline + impaired) ranging from 3.5 to 0.7 cases of abnormal tolerance to each case of diabetes in the lowest and highest body mass index categories respectively.

If one considers the total rate of diabetes in the body mass index categories $<23$ as representing the rate of non-obesity-related cases, it can be estimated that in our sample about $60 \%$ of the diabetes is associated with obesity. As our population is more obese than the USA [2] and (based on Dr. Jarrett's quotation) British populations, it may well be that in these countries the proportion of the obesity-related diabetes among diabetic patients is lower, perhaps even substantially so.

In view of Dr. Jarrett's plea to look for other risk factors for diabetes, it is of interest that preliminary analysis of interviews regarding recent habitual physical activity and diet conducted in a subsample of more than 500 individuals of our study group [3] indicated that, independent of the effects of body mass index and age, at all levels of body mass index and in both sexes the risk of abnormal glucose tolerance and diabetes in the upper tertile of energy expenditure was half that of less active individuals. No effect of total caloric intake or of specific food components was found.

Yours sincerely,

M. Modan, A. Karasik and H. Halkin

\section{References}

1. Modan M, Karasik A, Halkin H, Fuchs Z, Lusky A, Shitrit A, Modan B (1986) Effect of past and concurrent body mass index on prevalence of glucose intolerance and Type 2 (non-insulin-dependent) diabetes and on insulin response: The Israel study of glucose intolerance obesity and hypertension. Diabetologia 29: 82-89

2. Bray GA (ed) (1980) Obesity in America NIH publication no. 80-359, U.S. Departement of Health Education and Welfare, National Institutes of Health, pp 4-5

3. Modan M, Lubin F, Shitrit A, Lusky A (1986) Habitual diet, physical activity, body mass index and glucose intolerance. The Israel GOH Study. Diabetes 35 (Supply 1) (abstract, in press)

Dr. M. Modan

Departments of Clinical Epidemiology and Medicine A

The Chaim Sheba Medical Center

Tel Hashomer 52621

Israel

\section{Announcement}

2nd Annual Meeting of the Deutsche Gesellschaft für Adipositasforschung (German Society for the Study of Obesity).

This meeting will be held at the Rheinterrasse in Düsseldorf, FRG from 4-6 December 1986. The topics of the Meeting will include: obesity as a biological phenomenon; physiology and pathology of en- ergy metabolism; pathological anatomy. Abstracts for lectures or poster sessions should be submitted to Professor Dr. F. A. Gries or Professor Dr. Dr. L. Herberg, Diabetes Forschungsinstitut an der Universität Düsseldorf, Auf́n Hennekamp 65, D-4000 Düsseldorf 1, FRG by 20 September 1986 